\title{
TWEE BELANGRIKE TOEKOMSBEPALENDE TENDENSE OP KERKLIKE TERREIN
}

Prof. Hentie Boshoff.

As daar veral twee hoofgroepe van tendense is wat die kerk in die volgende dekade of twee dramaties gaan raak, dan is dit eerstens die demografiese of bevolkingsveranderinge wat besig is om plaas te vind en dan tweedens, houdingsveranderinge. Daar kan ander wees maar hierdie kan die mees dramatiese invloede hê.

1. Eerstens, wat bevolking aanbetref:

Ons is op hierdie stadium vinnig besig om na die punt te beweeg waar ons blankes se fertiliteitskoers na 2 daal m.a.w. waar die geboortes en die sterftes mekaar net uitkanselleer. Op die huidige stadium is dit reeds 2,01 . Omdat sommige mense nooit trou en kinders kry nie, het ons reeds die punt bereik waar geboortes en sterftes mekaar kanselleer. Ons verwag dat voor die einde van hierdie eeu die blankes s'n na 1,7 sal daal, d.w.s. dieselfde situasie as wat ons op die oomblik reeds in Wes-Duitsland en Frankryk het, naamlik waar die sterftekoers die geboortekoers oortref.

Die Kleurlinge en Asiërs is ook besig om dieselfde pad te volg, maar hulle fertiliteitskoers is nog nie naastenby waar die Blankes is nie. Die Kleurlinge s'n het dramaties gedaal. Waar dit 6,19 in 1945 was (m.a.w. 6,19 kind per gesin), staan dit op die oomblik op 2,9. Voor die einde van die eeu behoort dit ook onder 2 te daal. Die Asiërs is ook besig om dieselfde pad te loop. Die Swart fertiliteitskoers bly nog geweldig hoog, alhoewel daar aanduidings is dat dit in die stede dramaties daal.

'n Eerste belangrike saak wat ons moet raaksien, is dat, wat die Blankes betref, raak ons al meer ' $n$ volk van middeljariges en ou mense. Die mediaanouderdom van die Blankes is op die oomblik 25. Teen die einde van hierdie eeu behoort dit op 35 te staan, en teen die jaar 2010, 2020 sal dit ongeveer op 45 staan. Die kerk gaan dus al hoe meer ' $n$ middeljarige en oumenskerk word wat die Blankes betref. Teen die einde van die eeu sal na verwagting meer persone onder die Blankes bo 60 jaar wees, as wat daar onder 20 jaar sal wees. Die Kleurlinge sal in 'n mate ook hierdie tendens volg, terwyl veral by die Swartes die jonger geslag gaan domineer. Die mediaanouderdom onder die Swartes sal teen die einde van die eeu ongeveer 22 wees.

Hierdie verskynsel is nie nuut in die Westerse wêreld nie. Dit is die patroon wat dit in die ontwikkelde gemeenskappe volg: WesDuitsland is alreeds by 1,7 en die geboortekoers is dus dramaties laer as die sterftekoers. Dit beteken dan ook nie net dat ons kerklik gesproke 'n groter groep ou mense sal hê nie, maar ook dat die belange van die middeljarige en ouer mense relatief sterker sal weeg, as wat die jong mense se belange gaan weeg. Dit gaan faktore soos versorging meebring, wat vroeër nie op so 'n groot skaal, kerklik gesproke, nodig was nie. 
'n Tweede hooftendens t.o.v. die demografiese is rondom die hele kwessie van huwelik en egskeiding en alles wat daarmee saamhang. Wat huwelike aanbetref bly dit nog redelik konstant per 1000 van die bevolking. Dit is die een ligpunt wat 'n mens by die demografiese gegewens van die blankes kry, nl. dat dit nie lyk asof die huwelik besig is om uit die mode te raak nie. Dit ten spyte van die feit dat volgens die 1980 sensus daar al so iets soos 55,000 pare is wat bloot net saambly. Die interessante is dat daardie saamblyers se swaartepunte nie in die twintigerjare is nie - maar in die dertigerjare.

As ek sê dat huwelike per 1000 onder die Blanke nie besig is om af te neem nie, kry ons egter dat egskeidings dramaties toeneem. Vanaf die sestiger tot die tagtigerjare het die egskeidingskoers onder blankes omtrent vervyfvoudig. Die mediaanouderdom van huwelike het gedaal tot 7,3 jaar op die oomblik. Die normale patroon wat begin ontwikkel is dat die gemiddelde ouderdom waarop 'n vrou trou is so $22,5-22,9$ jaar. Die man trou hier in die orde van $24,5-24,9$. Dan kry ons die verskynsel dat die vrou gewoonlik so 2 jaar voltyds werk, haar beroep beoefen en haar kwalifikasies verbeter, dan huis toe gaan teen gemiddeld $25 / 26$ jaar, haar 2 kinders, wat die gemiddelde is, kort na mekaar kry en hier teen die ouderdom 30 of wanneer die oudste kind skooltoe gaan, keer sy redelik permanent terug na die beroepswêreld. Die beroepsvrouverskynsel begin hier teen die ouderdom 30 geweldig opskuif. Sy bly in die beroepsmark tot ongeveer $52 / 53$, d.w.s. tipies wanneer die kinders uit die skool gaan en die huis verlaat. Belangrik om op te let dat juis op dié stadium wat die kind in die skoolsituasie kom, begin die ma al meer ' $n$ beroepsvrou word.

Ons vind dat juis die ouderdom $30 / 32$ die kritiese ouderdom is waarop egskeidings dramaties begin toeneem. Nou is dit interessant dat die swaartepunt van die saamwoonverskynsel juis hier in die ouderdom 34/35 lê. Dit begin al duideliker blyk (daar word sake uitgemaak oor die belastingstruktuur wat dit bevorder) dat die belastingstruktuur maar 'n deel van die probleem is. In die V.S.A., waar vrouens afsonderlik belasting betaal, is die saamwoonverskynsel van die hoogste ter wêreld. Ten spyte van die belastingtoegewings het dit nie daar verander nie. Die tipiese verskynsel is dat hierdie vrou, wat aan die begin van ' $n$ beroepslewe kom en dan ' $n$ egskeiding beleef wel ' $n$ behoefte het aan ' $n$ man in die huis, maar nie weer kans sien vir 'n huwelik nie. Dan begin die saamblyery. Die tweede huwelik se mediaanouderdom is in die omgewing $35 / 36$ (vir die mans so 'n bietjie ouer).

Dit bring al meer die probleem mee dat die enkelouer-gesinne iets is wat toenemend mee saamgeleef sal moet word. Opnames wys duidelik dat onder vrouens en studente al hoe meer die opvatting posvat dat iets met jou kop fout is as jy jou sekuriteit op 'n man gaan plaas. Die man word nie meer as die hoofbron van sekuriteit deur baie van ons vrouens gesien a.g.v. hierdie onsekere huweliksituasie nie. Hulle soek al meer hul sekuriteit in 'n goeie opleiding. 'n Mens 
vind deesdae al hoe meer dat die studente wat die ernstigste is oor opleiding, of die mees gerigte vrae vra oor opleiding, dikwels die damesstudente is. Daarom dat ons al meer die situasie vind van die eenouergesin of die situasie van 'n vrou of man wat 'n kind wil hê, maar nie getroud wil wees nie. Veral in die stedelike komplekse begin hierdie verskynsel groot probleme skep. By 'n sekere stedelike Afrikaanse Laerskool waar $60 \%$ van die kinders uit enkelouergesinne kom, moes van die kinders die afgelope jaar sielkundige behandeling kry, omdat hulle dit nie kon verwerk nie. In Amerika word hulle die sgn. "key-children" genoem omdat hulle 'n sleutel om die nek dra om enige tyd in en uit te gaan by die woonstel of hotelkamer.

Hier lê toenemend vir die kerk 'n uitdaging, naamlik dat hy êrens hierdie kind sal moet begin akkommodeer. Ons sit met die gebroke situasie van die gebroke gesinne en hierdie kind wat dikwels of op straat grootword, of by bediendes of by kleuterskole waar hy miskien fisiese versorging kry, maar sy geestelike versorging soms in botsing is met dit wat hy by die huis/kerk kry. Die vraag word gevra waarom ons nie ons kerksale en ander fisiese fasiliteite in die week vir hierdie soort fasiliteite beskikbaar stel om daardeur die geleentheid aan te gryp dat die kerk by baie van die verwaarloosde gesinne kan uitkom nie. Die kind wat opgepas word, word die instrument om dan weer die ouer by die kerk te betrek en om hom weer meelewend te begin maak.

' $n$ Derde demografies tendens, is dat dit al meer lyk of die kindgesentreerde huisgesin in die toekoms nie meer so belangrik gaan wees soos wat dit histories die geval was nie. Ons kry in die eerste plek kleiner gesinne en tweedens die beroepsvrougedagte waar daar nie noodwendig tyd is om die kind se belange eerste te plaas nie. Die skole begin dit toenemend ondervind dat hulle net nie meer die ouers kan betrek op 'n skaal wat hulle dit vroeër kon doen nie, omdat ma en pa heeldag werk,

Hierdie verskynsel word meegehelp deur sgn. oorslaan-van-diejeug-sindroom. Kyk jy T.V. en jy sien dat 'n klein persentasie programme vir die jeug van belang is. Die oorgrote meerderheid is grootmensprogramme. Die kind (al is hy Laerskoolkind) word groot in 'n grootmenswêreld. Hy praat oor grootmensdinge op Laerskool. Jy sien dit in hulle kleredrag. Die jeug se kindweesfase word oorgeslaan in hierdie proses. Die probleem begin ontstaan dat hierdie kinders op 'n baie vroeë ouderdom by die diepkant ingegooi word en nie altyd weet hoe om te swem nie, want die ouer is nie altyd beskikbaar nie. Die kerk sal al meer en meer moet begin om, benewens kategetiese onderrig, ook mensvormingsonderrig te gee, en hom in sy totaliteit as mens te begin hanteer namate hy dit nie meer volledig in die ouerhuis kry nie.

II. ' $n$ Tweede hoofgroep van tendense is die sgn. Houdingsverandering.

Hier is die heel grootste veranderinge aan die gang.

Tradisioneel het ons geleef in 'n samelewing waar ons die Afrikaanssprekende redelik onder een kombers kon toemaak - hulle 
politiek, kultuur, idee van reg en verkeerd ens. was min of meer dieselfde gewees. Vandag begin ons ' $n$ diversiteit kry wat al duideliker word en wat finaal 'n skeiding gebring het onder die Afrikaanssprekende. Dit word gegrond op verskeie opnames.

Hierdie tendense is al die afgelope $7 / 8$ jaar aan die opbou. Dit dui daarop dat die verdeling onder die Afrikaanssprekende wat ons in die politiek en die kultuur begin kry, iets is wat finaal is en dat ons nie maklik weer 'n tipiese Afrikaanssprekende gaan kry waar almal dieselfde idees het nie.

Hierdie tradisionele Afrikanerdenke was basies gekenmerk deur 'n paar items - die familiegedagte was baie sterk,

- die nasionale identiteit,

- die protestantse werksetiek was sterk,

- rigiditeit in die sin van jy doen 'n ding net so en daar is nie ' $n$ tweede of derde manier om 'n ding te doen nie.

- Moreel en sedelik was daar redelik vaste idees oor hoe dinge gedoen word.

- Hiërargiese strukture het bestaan. Wat die volksleier of kerkleier sê is waar en word gevolg.

Tot 'n groot mate kon die Afrikaanssprekende onder daardie kenmerke geklassifiseer word. Ons begin al meer kry dat hierdie kenmerke eintlik net 'n faksie van ons Afrikaanssprekende verteenwoordig. Dis baie moeilik om 'n syfer hierop te plaas maar uit opnames lyk dit of dit so ongeveer $15 / 20 \%$ kan wees wat nog volledig onder hierdie groep val. Dit wil nie sê dat van die ander nie ook van hierdie kenmerke het nie, maar al wat ek daardeur kan sê is dat daar ongeveer ' $n 15 / 20 \%$ is waarom jy 'n kring kan trek en sê: "Dit is soos hulle lyk".

Baie van hierdie kenmerke kry jy ook by die ander Afrikaanssprekendes, die punt is egter dat daar 'n vloeibaarheid begin kom, dat jou Afrikaanssprekende nie net meer hierdie kenmerke het nie, maar ook ander kenmerke begin kry. Wat is nou hierdie ander kenmerke? Basies kan hierdie ander kenmerke in 3 groepe geklassifiseer word.

'n Eerste leiertendens wat veral onder die jonger en swakker opgeleide groep Afrikaners sterk na vore tree, is die verpersoonliking van dinge. Dit gaan in die samelewing net om homself en sy eie belange en jy kry niks met hom reg deur vir hom te vertel dat hy aan 'n groter groep, 'n gemeente, kerk, volk, behoort nie. Sy belange tel eerste en as iets nie in terme van sy eie belange oorgeskryf kan word nie, stel hy nie belang nie. In 'n groot mate is by hom 'n leef-vir-vandag sindroom baie sterk. Dit is die mens wat in die beroepsituasie 'n houding het van "l want a job with less future and more present". Sensasie is deel van hierdie mens se pakket, hy wil alles nuut ondervind. hy wil vry wees van alle reëls om hom, hy wil maak soos hy wil. By hierdie groep leef die opvatting sterk dat die samelewing en die kerk niks te sê het oor morele sake nie. As ek met 'n dame wil saamleef buite die huwelik dan is dit my eie private saak. Hy be- 
skou aggressie en alles wat daarmee saamhang as 'n geregverdigde metode - hy is die mens wat alles met skiet en slaan wil regkry. Verandering in Suid-Afrika word deur hulle as 'n bedreigi.g gesien en vir hulle het die laaste loopgraaf aangebreek; daar is net een manier om die veranderinge in ons land te voorkom en dit is deur weerstand te bied. Omdat hy net vir vandag leef sien hy geen sin in die toekoms en in die veranderinge nie - al wat hy daarin sien is bedreiging van die status quo en sy bevoorregte posisie. Hy moet iets daaraan doen en geweld is vir hom die mees aanvaarbare metode.

Die ontstellende is dat nie net die laer sosio-ekonomiese groepe hierdie houdings inneem nie, maar ook van die hoër sosio-ekonomiese groepe.

'n Tweede leiertendens wat aan die ontstaan is, is die materialise. Ons kry dit veral by die jonger-middeljarige en veral beroepsvroue. Materialisme, status en alles wat daarmee saamgaan word vir die mense die Alfa en die Omega van hul bestaan. Vir hulle is die kwantiteit van die lewe belangriker as die kwaliteit. Dit wat vir hulle sin aan die lewe gee is die materiële, die uiterlike statussimbole, die nuutste tegnologie (bv. motors, huishoudelike apparaat ens), oorheers hulle lewe. Vir hulle is morele en sedelike sake so 'n bietjie op die agtergrond. Dit is minder belangrik, maar om materieel vooruit te kom is van groter belang. Mens sien dit sterk in hierdie resessietoestande dat daar baie mense is wat net nie 'n verlaging in inkomste kan verwerk nie. Baie van die Blankes, met 2 witbrode onder die arm, kla omdat hulle bonus met 'n derde gesny is, terwyl daar grootskaalse werkloosheid is.

Veral die Pinkstergroepe teer op hierdie mense - veral die wat 'n materialistiese Godsdiens siening het. Daar word vir mense gesê dat as jy 'n Christen is, dan is jy mos ryk en dan sal dit goed gaan met jou en dit sal net beter gaan. Die mense verbind dan uiterlike welvaart met godsdiens. Die vraag gevra of ons nie partymaal besig is om hierdie dinge onbewustelik aanhelp nie. Bevorder ons dit nie dalk as ons die een wat die meeste bydrae gegee het se naam iewers noem nie. Dit verhef so 'n persoon tot 'n belangrike gemeentelid waarsonder 'n gemeente nie kan klaarkom nie. Help dit nie die materialisme aan nie?

'n Derde leiertendens wat 'n mens begin identifiseer onder die Afrikaanssprekendes is die groep wat getipeer kan word as iemand wat ' $n$ entjie die pad geloop het, gaan stilstaan en oor sy skouer kyk vanwaar hy vandaan kom in die lewe, en nie tevrede is nie. Hy begin vrae vra oor die materiële dinge, oor die "rat-race". Hy begin vrae vra oor die politiek oor sy werk. Dis die mense wat in 'n soort van 'n transformasie-situasie begin kom. Vir hulle raak dinge soos rassehar. monie belangrik. Hy het teruggekyk en gesien die pad wat hy gekom het, kan hy nie mooi mee saamstem nie. Hy begin vrae vra oor die samelewing en oor die kerk en dit waarvoor die kerk staan. Hy vra vrae oor gesag in die sin van hoekom moet hy net luister na wat die predikant sê as hy nie met hom saamstem nie, terwyl hy dalk oor 'n sekere saak 'n beter insig het. Dis nie 'n kwessie dat hy gesag as sulks 
verwerp nie, maar hy begin 'n skeiding bring tussen gesagsinhoud en gesagspersoon.

Wat werk aanbetref wil hy nie maar net 'n werk hê nie; hy wil 'n werk hê wat hom emosioneel bevredig en waarin hy kan groei as mens. Die kwaliteit van die lewe begin vir hom baie belangrik word. Om 'n mooi skildery te koop gee vir hom net soveel bevrediging as om 'n groot motor te koop.

Een van die baie belangrike kenmerke is dat hy met ander mense 'n emosionele band begin vorm. Hy wil nie net fisies met hom in kontak wees nie, maar ook emosioneel en andersins. Hierin kry ons een van die groot gronde vir die Koinoinia-gedagte, wat onder die Afrikaanssprekende jongmens begin leef, m.a.w. die gedagte dat geloof nie net kennis is nie, maar ook 'n vaste vertroue - dit het ook 'n gevoelsaspek. Daarom beskuldig hulle die Afrikaanse kerke dat hulle alles so klinies-verstandelik wil maak.

Dié mens begin oor ' $n$ al breër terrein van die samelewing vrac vra. Hy begin die historiese pad wat die Afrikaanssprekende geloop het te bevraagteken. Hy soek na nuwe gedagtes en nuwe denke, nuwe organisasiestrukture, veral in ons kultuur, politiek en kerk. Hierdie groep is gewoonlik goed opgelei. Dis 'n tipiese sindroom van die namatriek geskoolde mens, wat al sterker in hierdie groep begin inbeweeg. Dit is die groep wat na my mening in die toekoms onder dic Afrikaanssprekende al sterker gaan groei.

Dit wil nie sê dat die ander twee groepe nie ook aan die groei is nie. Wat die eerste groep, die loopgraafgroep betref, hang dit af in hoe 'n mate die politieke veranderinge in ons land gehanteer gaan word. As dit te vinnig gaan plaasvind, dan wil dit lyk of daardie groep baie vinnig sal groei. Dit sal gebeur as die veranderinge op politieke, sosiale en maatskaplike terrein die aanvaarbaarheidsdrumpel van die mense oorskry. 'n Soort van opstand onder die mense in die vorm van 'n verregse blanke ANC is dan nie vergesog nie.

Die Kerk het 'n groot taak om hierdie mense kerklik te akkommodeer, maar ook om sy houdings en strewes so te temper, dat daar ook vir ander mense en ander kleurgroepe in hierdie land plek en ruimte gegun word.

Wat die materiële groep betref, is dit 'n logiese ontwikkeling. Die huidige geslag is die eerste groep Afrikaners wat nie groot geword het met die depressie-sindroom nie. Die geslag wat grootgeword het in die dertigerjare het dikwels 'n "depressie-sindroom". Hulle kom ekonomies uit 'n baie harde tyd waarin elke sent belangrik was. Hulle wou spaar, hulle wou vir hulle kinders die beste gegee het. Nou kry ons 'n geslag wat gront geword het in die sgn. "affluent society", wat dit materieel baie goed mee gaan. Hierdie groep begin nou vir die eerste keer die stadium binnegaan waar hulle materieel nie meer broodsgebrek het en kan koop wat hulle wil. Hulle begin dit dan ook demonstreer op 'n baie groot skaal. Die Engelssprekende het tot 'n groot mate reeds in die veertigerjare deur daardie fase gegaan en hy is baie sterk by die kwaliteit-van-die-lewe-gedagte waarin hy agtergekom het dat die materiële dinge nie daardie bevrediging en geluk 
gee wat hy belowe om te gee nie. Daarom is dit logies dat die Afrikaanssprekende baie sterk in hierdie groep sal inbeweeg.

Die vrae: (Die vrae self is nie op band geneem nie, slegs die antwoorde).

'n Vraag is gevra met verwysing na Alvin Toffler se "The Third Wave" - die tegnologiese golf:

Prof. Boshoff: Kyk na John Naisbitt se "Megatrends". Hierdie groep wat begin stilstaan en terugkyk en nie tevrede is met sy lewe nie, word in hierdie boek mooi beskryf.

John Naisbitt se boek is gegrond op sy werk die afgelope dekade. Sy organisasie monitor elke dag \pm 400 Amerikaanse tydskrifte en koerante. Net dit wat belangrik is kom in die koerante. As 'n saak nie belangrik is nie, dan kom dit nie in die koerant nie. As jy dus sake wat verskyn monitor, kan jy uiteindelik baie goeie neigings opmerk.

So kom sekere verskynsels en woorde in ons samelewing baie sterk voor, soos die woord verandering, die woord vrees, die woord rasseverhoudinge. Oor morele en sedelike sake, oor bv. dobbel, kry jy baie min wat gepubliseer word. Dis nie dinge waaroor mense meer bekommerd is nie.

Een van die kenmerke van hierdie groep wat oor sy skouer be. gin kyk, is dat hy in opstand kom teen die tegnologie. In die sestigerjare het ons geleef in die era van naas God die Tegnologie. Dit wat tegnologies reg was, was aanvaarbaar. Maak nie saak of dit vir die samelewing nadelig was nie, ons het dit aanvaar. Nou begin die situasie ontstaan dat die mens die tegnologie begin bevraagteken, $b v$ : die Groene-beweging in Wes-Duitsland. Hulle hele bestaan is gegrond op die feit dat hulle kernkrag as 'n nie-aanvaarbare energiebron sien. Hulle neem toe in Europa, soveel sodat die uraanmark daardeur ernstig geknou word.

In die V.S.A. kry mens 'n ander voorbeeld van hierdie weerstand. Tegnologies het die "electronic-cottage", moontlik geraak. Jy hoef nie meer by 'n kantoor te sit en werk nie jy sit by 'n terminaal en werk. Jy kan die sgn. fondsoordraging uit jou huis doen. Bel-tel maak vergaderings uit jou huis of kantoor moontlik. Algemeen word verwag dat ons 'n kontantlose gemeenskap gaan hê, vergaderings oor 'n telefoonnetwerk hou.

Naisbitt wys die interessante dat, ten spyte van hierdie tegnologiese ontwikkeling, wat effektief en kostebesparend is die hou van vergaderings eerder vermeerder as verminder. Vliegtuigritte het vermeerder. Besighede wat die "electronic-cottage" stelsels begin het, sluit weer. Hoekom? Omdat die mens in opstand kom teen die onpersoonlikheid van die tegnologie. Hy wil nog die persoonlike verhouding handhaaf, hy wil geld in sy hand voel. Tjekrekenings is duurder as om by 'n terminaal jou geld te trek; nogtans verdwyn tjekrekenings nie. Die mens wil nog in beheer van sy situasie wees.

Die vinnigste groeiende beroep in die V.S.A. is die van die vroedvrou, omdat die hospitale so klinies-effektief en onpersoonlik geword het dat die Amerikaanse vrou daarteen in opstand kom. Sy wil haar kind by die huis kry en dit doen binne hierdie persoonlike 
situasie. Die mensberoepe neem toe. Dit raak 'n geval van "hi-tech needs hi-touch to survive".

Wat tegnologie en die toekoms betref kan jy hoogstens van alternatiewe praat wat aan die ontwikkel is. Daarom is die "Third Wave" maar een moontlike scenario wat kan gebeur. Daar kan ook die beweging kom wat genoem word "back to basics", back to nature". Dis die mense wat die "rat-race" heeltemal los en geĩsoleerd 'n eie bestaan probeer maak op sy plasie, waar die klem geplaas word op gesonde werk en gesond lewe.

Histories was die geloof dat, wat gesondheid betref, jy eers siek moet word, dan sal die tegnologie jou genees. Nou kry ons 'n holistiese gesondheidskonsep, waar voorkomend te werk gegaan word. Hierin lê die grondrede van die sgn. "salad-bars", jou gesond-eet-gedagte, die "joggers" en dat jy gesond moet leef, dan sal jy minder siektes hê.

Volgens Toffler sou dit nie kon gebeur omdat ons net op pad was van die vertegnologisering van die samelewing.

'n Ander vraag i.v.m. demografie?,

Prof. Boshoff: Dit is so dat die realiteit al duideliker begin word dat ons land hoogstens ' $n$ bevolking van so $80 / 85$ miljoen mense sal kan dra, veral wat die fisiese hulpbronne soos water betref.

Tegnologie kan verbeter. Maar dit is so dat as ons bevolkingsaanwas, veral wat die swartes aanbetref, teen die huidige tempo toeneem, dan sal ons hier teen die jaar 2020/30 'n Swart bevolking hê in die orde van 130 miljoen. Indien ons nie teen die einde van die eeu die fertiliteit van alle bevolkingsgroepe kan afkry na 2,1 nie sal ons uit die oogpunt van ons hulpbronne nie ons bevolking kan dra nie. Alle belastinggeld sal dan net vir basiese dienste soos gesondheid en opvoeding gebruik word en daar gaan niks oor wees vir ontwikkeling nie.

Maar nou, ons het dan juis weer nie genoeg opgeleide mense nie wat die wa deur die drif gaan trek nie. Teen die einde van die eeu sal ons aan alle vorme van bestuurswerkers min of meer so 200,000 addisioneel nodig hê. $\mathrm{Na}$ berekening sal die Blankes hoogstens 80,000 van die 200,000 kan lewer, a.g.v. die feit dat daar net nie die getalle sal wees nie. Tweedens sal dit gebeur a.g.v. die normaalverdeling. Nie alle Blankes kan bestuurders word nie. Omtrent so 16 tot $18 \%$ van 'n bevolking het die vermoë om naskoolse opleiding te ondergaan, en jou bestuursposte te vul. Wat die tegnies-geskooldes betref is die krisisse nog groter.

Histories het omtrent $96 \%$ van die bestuursposte uit die Blanke groep gekom. Daar sal van die Blanke kant net nie genoeg mense wees om die ekonomie te organiseer nie. In die westerse kapitalistiese wêreld word dit algemeen aanvaar dat 1 entrepreneur/bestuurder dra min of meer 10 tot 14 werkers op sy rug. In Suid-Afrika is dit op die comblik $1: 52$. As ons nie ons hele opleidingspatroon verander kan kry dat anderskleuriges ook in hierdie groepe ingetrek word nie, dan is dit nie snaaks dat dit teen die einde van die eeu $1: 80$ sal wees nie. As dit in die weste $1: 14$ is, ons is nie so goed om in Suid- 
Afrika 52 werkers op 1 blanke se rug te laai nie en nog dieselfde produktiwiteit te kry nie. Ons is net besig om onsself uit die wêreldmark te prys a.g.v. hierdie situasie. Die Blankes is hiertoe instrumenteel met die kleinerwordende gesinne.

Die realiteit begin na vore kom dat ons die anderskleuriges in massas by die bestuursposte sal moet betrek, maar die vraag is of die skoolstelsel in staat is om dit te kan doen.

Is die gehalte van onderwysers van anderskleuriges altyd op standaard? Dis waar die probleem kom. Dit gaan nie net om matriek of 'n graad nie. Dit gaan ook om 'n hele ervaringswêreld, wat jy nie vanuit 'n skoolsituasie kan verwerf nie.

Dit word bereken dat as die planne van die De Lange-kommissie in werking gestel moet word, sal ons geen geld hê vir iets anders nie. As ons westerse standaarde op onderwys wil toepas sal daar nie genoeg geld wees nie. Erens sal 'n totale verandering in ons hele onderwysdenke moet kom in die sin van dat ons nie op die tradisionele manier sal kan skoolhou van 1 onderwyser per 30 kinders en sekere fasiliteite wat net vir sekere groepe eksklusief is nie.

Vraag: Wat kan gedoen word?

Oor die skouerkykers - Is die predikante nie besig om oor die skouers te kyk en niks het in die verlede gewerk nie en nou moet ons iets doen om hierdie ramp af te weer.

Die neigings in Amerika, die terugkeer tot die natuur - is daar nie 'n soort van 'n ingeboude meganisme in die natuur en samelewing om weer te balanseer, sonder 'n georganiseerde toedoen van sekere instansies - 'n pendulum-aksie.

Dan, wat staan die predikante te doen - die jeug dinge.

Ek is bang vir 'n paniekerige doen van 'n klomp bykomstige

Prof. Boshoff:

Oor die hele kwessie van die terugswaai van die pendulm - dit is so. Mens moet nie onnodig alarmisties wees nie. Baie dinge bekommer ' $n$ mens, maar daar is ook baie dinge wat daarop dui dat daar 'n teenrevolusie aan die gang is. Daarom deel ek nie die siening van "trend is destiny" nie. Daar kom teen reaksie teen die tegnologie. In sewentigerjare was die saamblystorie op sy hoogtepunt; so ook voorhuwelikse seks. Nou raak kuisheid weer hoog in die mode veral onder die jongmense. As die pendulum terugswaai gaan dit nie tot die uiterste terug nie.

Wat kan gedoen word, sonder om oor te reageer, of metodes te ontwerp wat nou nie heeltemal met die stroom saamgaan nie. As daar een ding is wat tans baie duidelik na vore tree, veral onder jongmense dan is dit 'n skipbreuk van sekerhede. Die sekerhede van die sestigerjare het nou onsekerhede geword. Ons weet nie presies mooi waarheen is ons op pad met die politiek nie.

Op ekonomiese terrein het ons 'n skipbreuk van sekerhede. Werkloosheid begin vandag 'n baie ernstige saak word. Op die oomblik sit professionele mense werkloos. Inflasie het 'n omvang begin aan- 
neem wat mense begin moedeloos maak. Op morele en ander terreine geld soveel verskillende uitsprake. Oor baie min dinge het die mens regtig sekerheid. Daar is 'n ontsaglike behoefte om te weet wie is $\mathrm{ek}$, wat is die sin van my lewe, die sin van my bestaan, waarheen is ek op pad? Daarin lê die uitdagings as ons by praktiese dinge wil kom, naamlik dat ons ons mense weer 'n slag by die A B C van die geloof moet bring. Dit wat regtig basies en onveranderlik is en dit wat minder belangrik is, moet onderskei word. Juis in 'n vinnig-veranderende samelewing kry jy al meer die neiging na eksistensialisme. Omdat niks meer vas is nie, maak niks ook meer sin nie. Dit is juis dan wat die mens begin soek na wat onveranderlik is, wat verander regtig nie.

In hierdie rigting moet ons beweeg. Ons mag nie reageer en sê alles het nou gefaal en nou moet ons heeltemal iets nuuts ontwerp. Dan is ons besig om hierdie onsekerheidsindroom nog verder aan te jaag.

Samevattende opmerkings van Prof. Boshoff:

Van die kant van die kerk word die verantwoordelikheid van die mens beklemtoon, maar ons bly in gebreke om prakties vir die mense te wys hoe kan hy aan hierdie "deurmekaar samelewing" iets konkreets doen om te verhoed dat dinge heeltemal hande uitruk. Daar moet vir die mens 'n toekomsvisie gebou word. In kerklike opsig is ons so besig met die ewigheidsperspektief, die hiernamaalse perspektief, dat ons nie die aardse toekomsperspektief verkonkretiseer nie. Ons moet leiding gee hoe kan hy as doodgewone lidmaat iets aan hierdie probleme begin doen, al is dit met verbeterde houdings en gesindhede. As ons nie die gesindhede kan verander nie, dan sal die potensiaal van 'n bloedbad in S.A. styg.

As ons mense se houdings kan verbeter sodat rasseharmonie ook deel van sy toekomsperspektief is, dat ons ook bereid is om bietjie minder van die koek vir onsself te kry, kan ons al soveel meer hierdie revolusiepotensiaal ontlont. In daardie opsig kan die kerk 'n belangrike rol speel.

Ons moet ophou met die alarmistiese sienings wat vir ons mense net 'n donker prentjie wys so asof daar geen hoop meer is nie. Al lyk dit sake loop in 'n sekere rigting, beteken dit nie dat ons nie iets daaraan kan doen nie. Veral aan die jong mense kan die kerk iets doen wat houdingsverandering betref.

Belangrik is die gedagte van spesialisasie of diversifikasie in die bediening van die kerk, omdat jy diversiteit onder mense begin kry. Die persoon wat die ouer lidmaat bearbei gaan nie noodwendig net so suksesvol die jong lidmaat bearbei nie. Hier sal 'n verskuiwing moet kom.

Vir die jongmens is die voorbeeld wat die predikant stel, belangriker as wat die predikant sê. Hy kan die mooiste dinge vertel, maar as hy dit nie uitleef nie, oortuig dit nie. Die sensitiwiteit van die predikant vir sy teikengroep moet baie skerp wees. Die eksistensiële mens vra nie altyd na die beginsel nie, maar na die voorbeeld.

Verder is dit belangrik by die mens en sy eie probleme uitge- 
kom moet word. Ons moet wel die hiernamaalse perspektief vir hom gee, maar ook prakties aantoon wat hier en nou gedoen kan word in hierdie bedeling.

Kleiner groepsbearbeiding is noodsaaklik en daarvoor is mannekrag nodig. Die gemeentelede sal opgelei moet word om sekere take binne die kerk te behartig bv. kategese.

Gelewer voor GTV Witwatersrand. 